\title{
Morbidity and mortality of black HIV-positive patients with end-stage kidney disease receiving chronic haemodialysis in South Africa
}



South Africa (SA) has the highest prevalence of HIV/AIDS of any country in the world, with 6.3 million people living with $\mathrm{HIV}^{[1]}$ This high rate of infection adds complexity to a health system already overwhelmed by chronic kidney disease (CKD), particularly that caused by hypertension, diabetes and chronic glomerulonephritis.

Renal disease is common in HIV-infected individuals, affecting up to $30 \%$ of patients, and is associated with increased morbidity and mortality. ${ }^{[2-5]}$ In SA, the spectrum of renal disease in HIV has been accumulating from renal biopsy data. ${ }^{[4,6]}$ HIV-associated nephropathy (HIVAN ${ }^{[7,8]}$ is the most common renal biopy finding and progresses rapidly to end-stage renal disease (ESRD) if the patient does not receive antiretroviral therapy (ART) $\cdot^{[4]}$ Other causes of renal disease in HIV-positive patients include tubulointerstitial nephritis from tuberculosis, drugs (tenofovir, rifampicin, sulfamethoxazole plus trimethoprim, amphotericin), and acute kidney injury due to sepsis. ${ }^{[9]}$ The prevalence of ESRD is projected to increase further, as there is an emerging collision of epidemics of communicable and non-communicable diseases. HIV-positive patients are living longer on ART, with a rising incidence of the diseases of lifestyle including hypertension and diabetes. ${ }^{[10]}$

Black Africans, who are most affected by the HIV epidemic, also have a genetic predisposition to HIVAN. Epidemiological data confirm that African Americans in the USA are more prone to CKD than any other ethnic group. ${ }^{[1]}$ The risk of ESRD has been reported to be three- to six-fold higher in African American than in Caucasian HIV-infected patients. ${ }^{[12]}$ HIVAN represents a huge disease burden and is ranked as the third leading cause of ESRD among blacks aged 20 - 64 years in the USA, lagging behind diabetes and hypertension. ${ }^{[13]}$ Fortunately, ART has reduced the incidence of HIVAN and ESRD among African Americans ${ }^{[14]}$ and black South Africans. ${ }^{[4]}$

Until recently, the magnitude of CKD and the number of persons accessing renal replacement therapy in SA have been poorly documented. However, SA has taken positive steps to reinstate a functional renal registry, which confirms that currently $8.5 \%$ of 4637 chronic dialysis patients in the country are HIV-positive. ${ }^{[15]}$ However, this number is underestimated owing to exclusion of a substantial number of HIV-positive patients from state sector dialysis units, because state hospitals require their patients to be transplantable in order to gain access to chronic dialysis. Given the risk of posttransplant comorbidities, it is mandatory for HIV-positive patients to have a CD 4 count $>200$ cells $/ \mu \mathrm{L}$, to have a suppressed viral load, and to have been stable on ART for 6 months in order to be considered for most state sector chronic dialysis ${ }^{[16]}$ Patients who do not fulfil these criteria are excluded from most state units.

Prior to availability of ART, HIV was a death sentence for individuals with CKD. Several studies suggested that survival rates were dismal, and owing to the poor prognosis, chronic renal replacement therapy (RRT) was rarely offered to patients. ${ }^{[17]}$ This was particularly true in SA. Since introduction of ART, the overall survival of HIV-positive patients has increased dramatically. SA, which has the largest HIV treatment programme in the world and average treatment initiation rates of 30000 per month, ${ }^{[1]}$ now has a parallel need for increased access to RRT.
Since ART roll-out there has been growing evidence of little difference in survival between HIV-infected patients who are receiving efficacious ART compared with the general population on dialysis. ${ }^{[17]}$ After comparing survival between 5299 patients who received haemodialysis and 716 who received peritoneal dialysis (PD), the United States Renal Data System has also reported that dialysis modality is not a factor in survival of patients with HIVAN (hazard ratio: peritoneal dialysis v. haemodialysis $1.04,95 \%$ confidence interval (CI) $0.96-1.13){ }^{[18]}$ However, the study was limited by the lack of information regarding CD4 counts and viral loads. In the pre-ART era, the proportion of patients with peritonitis in the HIV-infected population treated with PD was not different from that of the HIVnegative population treated with $\mathrm{PD}{ }^{[19]}$ Gorrin et al. ${ }^{[20]}$ demonstrated an increase in overall survival and a decrease in PD-associated complications compared with previous studies. In this small study of eight HIV-positive patients, cardiovascular events were the main cause of death (two patients, 25\%). However, until large studies are conducted, controlling for stage of HIV infection and other comorbidities, selecting dialysis modality for HIV-infected patients should be similar to other patients with ESRD.

Although the evidence is encouraging regarding RRT in HIVpositive patients, the Dialysis Outcomes and Practice Patterns Study (DOPPS) ${ }^{[21]}$ concluded that HIV-positive patients are at increased risk on haemodialysis. This study pooled data among haemodialysis patients in Europe, Japan and the USA and confirmed a nearly three-fold greater mortality risk on haemodialysis among individuals with HIV infection (relative risk (RR) 2.96; $p<0.0001$ ), with most deaths during the first year of dialysis (RR 5.60; $p<0.01$ ), but once again did not distinguish between those currently receiving or not receiving ART. ${ }^{[21]}$

It is well documented that transplantation is the best treatment option for CKD in patients without HIV. In spite of the cost of the operation and of immunosuppressive medication, it is also the most cost-effective treatment option. Given the high haemodialysis mortality seen in the DOPPS, should we not be striving for dialysis to be the bridge to transplantation in HIV-positive patients? Being HIV-positive was previously an absolute contraindication to renal transplantation. With the advent of ART, renal transplantation using HIV-negative donor kidneys in positive recipients has been employed successfully for HIV-infected patients with ESRD. ${ }^{[22]}$

In a prospective study by Mysore et al. ${ }^{[23]}$ (presented at the American Transplant Congress 2008) long-term survival was described in 132 HIV-positive patients with ESRD listed for kidney transplantation during February 2001 and December 2006. Half the cohort (65 patients) received kidney transplants and the other half (67 patients) remained on dialysis while waiting for kidney donation. The selection criteria for waiting list placement included maintenance on ART with a suppressed viral load and an absolute CD4 count of 200 cells $/ \mu \mathrm{L}$. The primary endpoint was patient death. Patient survival in the transplant v. the dialysis group at 1 year was $91 \%$ v. $89 \%(p=0.9)$ and at 5 years $80 \%$ v. $26 \%(p=0.000)$. Despite equal therapeutic suppression of HIV infection with ART and similar comorbid factors, kidney transplantation significantly prolonged 5-year patient survival in HIV-positive patients compared with dialysis in this study. 
In SA, places on state dialysis programmes are severely restricted. There are additional problems of long waiting lists for transplantation and limited consent to organ donation. HIV-infected patients, like many others with comorbidity, are often denied treatment, while kidneys from HIV-infected deceased donors are discarded. ${ }^{[24]}$ Transplantation of kidneys from HIV-positive donors to positive recipients has been pioneered at Groote Schuur Hospital, Cape Town, SA, significantly increasing the pool of donor kidneys to the advantage of both HIV-positive and HIV-negative patients. ${ }^{[25]}$ To date, 29 HIV-positive individuals have been transplanted with kidneys from HIV-infected cadaver donors. Preliminary data are extremely promising: 1-year patient survival is $86.36 \%$ and 3-year survival $72.73 \%$, and graft survival is $90.91 \%$ at 1 year and $80.81 \%$ at 3 years. ${ }^{[26]}$ Transplanting HIVinfected patients with kidneys from HIV-positive donors represents a significant advance in our resource-constrained environment.

In this issue of the $S A M J$, Fabian et al. ${ }^{[27]}$ demonstrate that haemodialysis in black African HIV-positive patients in the private sector in SA imparts excellent overall survival in spite of higher hospital admission rates and higher morbidity from infection (particularly vascular access-related infections) compared with HIV-negative patients. This study contributes to the growing data reflecting good outcomes for HIV-positive patients on dialysis. However, in Fabian's cohort a high proportion of patients had unexplained suboptimal viral suppression rates that would disqualify them as transplant recipients.

In resource-restricted settings such as SA, attention needs to be geared towards prevention of CKD and slowing progression towards ESRD. HIV contributes to a high risk of CKD, and as such HIV-positive patients should be screened for CKD at their first encounter with any health service. This is particularly important in view of the fact that HIVAN can occur with high CD4 counts. ${ }^{[4]}$ Screening should include urinalysis and measuring kidney function. Strategies should include fast-tracking for ART for patients manifesting renal involvement, awareness of tenofovir and sulfamethoxazole-trimethoprim toxicity, avoidance of nephrotoxic agents such as non-steroidal anti-inflammatory drugs, adequate fluid resuscitation when necessary, and efficient treatment of sepsis. ${ }^{[9]}$

Patients are living longer on ART and as such are at increased risk of developing hypertension and diabetes. ${ }^{[10]}$ Diseases of lifestyle may emerge as a new epidemic in the HIV-positive population. Those who provide healthcare to HIV-positive patients need to be aware of the special renal issues relevant to HIV, and the potential for evolution to ESRD, and should work actively with HIV and nephrology specialists to improve the outcome and quality of life of patients.

\section{Nicola Wearne \\ Division of Nephrology, Department of Medicine, Groote Schuur Hospital, Cape Town, South Africa} 1. UNAIDS. Country progress report 2012 - South Africa 2014 http://www.unaids.org/en/
regionscountries/countries/southafrica (accessed 4 October 2014).

2. Gupta SK, Mamlin BW, Johnson CS, Dollins MD, Topf JM, Dube MP. Prevalence of proteinuria and the development of chronic kidney disease in HIV-infected patients. Clin Nephrol 2004;61(1):1-6. [http:// dx.doi.org/10.5414/CNP61001]

3. Wyatt CM, Hoover DR, Shi Q, et al. Pre-existing albuminuria predicts AIDS and non-AIDS mortality in women initiating antiretroviral therapy. Antivir Ther 2011;16(4):591-596. [http://dx.doi. org/10.3851/IMP1766

4. Wearne N, Swanepoel CR, Boulle A, Duffield MS, Rayner BL. The spectrum of renal histologies seen in HIV with outcomes, prognostic indicators and clinical correlations. Nephrol Dial Transplan 2012;27(11):4109-4118. [http://dx.doi.org/10.1093/ndt/gfr702]

5. Szczech LA, Hoover DR, Feldman JG, et al. Association between renal disease and outcomes among HIV-infected women receiving or not receiving antiretroviral therapy. Clin Infect Dis 2004;39(8):11991206. [http://dx.doi.org/10.1086/424013]

6. Gerntholtz TE, Goetsch SJ, Katz I. HIV-related nephropathy: A South African perspective. Kidney Int 2006;69(10):1885-1891. [http://dx.doi.org/10.1038/sj.ki.5000351]

7. D'Agati V, Suh JI, Carbone L, Cheng JT, Appel G. Pathology of HIV-associated nephropathy: A detailed morphologic and comparative study. Kidney Int 1989;35(6):1358-1370. [http://dx.doi.org/10.1038/ ki.1989.135]

8. Rao TK, Friedman EA. AIDS (HIV)-associated nephropathy: Does it exist? An in-depth review. Am J Nephrol 1989;9(6):441-453. [http://dx.doi.org/10.1159/000168011]

9. Swanepoel CR, Wearne N, Duffield MS, Okpechi IG. The evolution of our knowledge of HIVassociated kidney disease in Africa. Am J Kidney Dis 2012;60(4):668-678. [http://dx.doi.org/10.1053/j. ajkd.2012.04.034]

10. Kalyesubula R, Wearne N, Semitala FC, Bowa K. HIV-associated renal and genitourinary comorbidities in Africa. J Acquir Immune Defic Syndr 2014;67(Suppl 1):S68-S78. [http://dx.doi.org/10.1097/ QAI.0000000000000259]

11. United States Renal Data System 2010 Annual Data Report: Atlas of Chronic Kidney Disease \& EndStage Renal Disease in the United States. Am J Kidney Dis 2011;57(1, Suppl 1):e1-e526.

12. Lucas GM, Lau B, Atta MG, Fine DM, Keruly J, Moore RD. Chronic kidney disease incidence, and progression to end-stage renal disease, in HIV-infected individuals: A tale of two races. J Infect Dis 2008;197(11):1548-1557. [http://dx.doi.org/10.1086/587994]

13. Ross MJ, Klotman PE. Recent progress in HIV-associated nephropathy. J Am Soc Nephrol Ross MJ, Klotman PE. Recent progress in HIV-associated nephropathy. J
2002;13(12):2997-3004. [http://dx.doi.org/10.1097/01.ASN.0000040750.40907.99]

14. Cosgrove CJ, Abu-Alfa AK, Perazella MA. Observations on HIV-associated renal disease in the

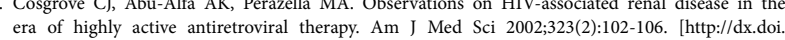
era of highly active antiretroviral therap
org/10.1097/00000441-200202000-00009]

15. Davids MR, Marais N, Jacobs JC. South African Renal Registry Annual Report 2012. Cape Town: South African Renal Society, 2014.

16. Swanepoel CR, Wearne N, Okpechi IG. Nephrology in Africa - not yet uhuru. Nat Rev Nephro 2013;9(10):610-622. [http://dx.doi.org/10.1038/nrneph.2013.168]

17. Mandayam S, Ahuja TS. Dialyzing a patient with human immunodeficiency virus infection: What nephrologist needs to know. Am J Nephrol 2004;24(5):511-521. [http://dx.doi.org/10.1159/000081041]

18. Ahuja TS, Collinge N, Grady J, Khan S. Is dialysis modality a factor in survival of patients with ESRD and HIV-associated nephropathy? Am J Kidney Dis 2003;41(5):1060-1064. [http://dx.doi.org/10.1016/ S0272-6386(03)00204-X]

19. Kimmel PL, Umana WO, Simmens SJ, Watson J, Bosch JP. Continuous ambulatory peritoneal dialysis and survival of HIV infected patients with end-stage renal disease. Kidney Int 1993;44(2):373-378. and survival of HIV infected patients w
[http://dx.doi.org/10.1038/ki.1993.254]

20. Gorrin MR, Rivas JLM, Garcelán MCA, et al. Outcome of HIV-infected patients of peritoneal dialysis: Experience in a center and literature review. [Evolución de los pacientes infectados por el VIH en
enting diálisis peritoneal: Experiencia de un centro y revisión de la literatura] Nefrología 2008;28(5):505-510.

21. Goodkin DA, Bragg-Gresham JL, Koenig KG, et al. Association of comorbid conditions and mortality in hemodialysis patients in Europe, Japan, and the United States: The Dialysis Outcomes and Practice Patterns Study (DOPPS). J Am Soc Nephrol 2003;14(12):3270-3277. [http://dx.doi.org/10.1097/01. ASN.0000100127.54107.57]

22. Stock PG, Barin B, Murphy B, et al. Outcomes of kidney transplantation in HIV-infected recipients. N Engl J Med 2010;363(21):2004-2014. [http://dx.doi.org/10.1056/NEJMoa1001197]

23. Mysore S, Anil K, Shahid M, et al. In HIV+ patients with end stage renal disease (ESRD) kidney transplantation significantly prolongs long-term patient survival compared to chronic dialysis treatment. Presented at the plenary session (1 June) at the American Transplantation Congress 2008, Toronto, Canada, 31 May - 4 June 2008.

24. Benatar SR. Health care reform and the crisis of HIV and AIDS in South Africa. N Engl J Med 2004:351(1):81-92. [http://dx.doi.org/10.1056/NEJMhpr033471]

25. Muller E, Barday Z, Mendelson M, Kahn D. Renal transplantation between HIV-positive donors and Muller E, Barday Z, Mendelson M, Kahn D. Renal trat
recipients justified. S Afr Med J 2012;102(6):497-498.

26. Muller M. HIV positive to positive transplantation. Presented at the World Congress of Transplantation, San Francisco, 30 July 2014.

27. Fabian J, Maher HA, Clark C, Naicker S, Becker P, Venter WDF. Morbidity and mortality of black HIVpositive patients with end-stage kidney disease receiving chronic haemodialysis in South Africa. S Afr Med J 2015;105(2):110-114. [http://dx.doi.org/10.7196/SAMJ.8369] 